Article

\title{
Hypervelocity Impact Cratering on Semi-Infinite Concrete Targets of Projectiles with Different Length to Diameter Ratios
}

\author{
Yangyu Lu, Qingming Zhang *, Yijiang Xue, Cheng Shang ${ }^{\circledR}$, Wenjin Liu, Siyuan Ren and \\ Renrong Long
}

State Key Laboratory of Explosion Science and Technology, Beijing Institute of Technology, Beijing 100081, China; luyangyubit@163.com (Y.L.); 3120130056@bit.edu.cn (Y.X.); chengshang0311@163.com (C.S.); lwj931@163.com (W.L.); yuandermail@yeah.net (S.R.); longrenrong@bit.edu.cn (R.L.)

* Correspondence: qmzhang@bit.edu.cn

Received: 20 May 2020; Accepted: 1 June 2020; Published: 5 June 2020

check for updates

Featured Application: the research content of this article may provide a reference for military defense engineering as well as shielding design for aerospace applications.

\begin{abstract}
Impact cratering experiments were performed on semi-infinite concrete targets with $7 \mathrm{~mm}$-diameter $40 \mathrm{CrNiMo}$ steel long-rod projectiles at impact velocities ranging from $2117 \mathrm{~m} / \mathrm{s}$ to $3086 \mathrm{~m} / \mathrm{s}$ by using a two-stage combustion light-gas gun. After the impact experiments, the crater diameter and depth as well as the crater volume were carefully measured. The concrete fragments were collected from the target chamber and the fragment mass was measured. The size of the crater (including the volume, diameter, and depth) and the fragment mass increased with increasing impact velocities, while the fragment distributions at different impact velocities were almost the same. Scaling laws for the crater volume impacted by the rod-shaped projectile were discussed and an empirical formula of crater volume was determined by the experimental data from the literature. Through the verification of the present experimental results, the predictive ability of the empirical formula proved to be reliable. Scaling laws for the size distribution of concrete fragments were also discussed. The normalized fragment mass distribution was proportional to the impact velocity raised to the power 1.5.
\end{abstract}

Keywords: impact cratering experiments; long-rod; concrete; fragment distribution

\section{Introduction}

With the development of hypersonic vehicle technology, it has been possible to load warheads at multiple or even tens of times the velocity of sound. A new type of weapon, a hypersonic kinetic energy penetrating weapon, has become a research hotspot in the international military field. This weapon uses the huge kinetic energy of a hypervelocity high-hardness and high-density alloy rod to destroy the target directly. An impact crater is one of the typical forms of target damage when hypervelocity projectiles penetrate the target material-e.g., concrete. However, due to the limitations of laboratory launching technology, there are only a few experimental studies available, dealing with the hypervelocity impact of long-rod projectiles on concrete targets. At present, the research on impact craters deals mainly with craters caused by spherical projectiles, which are linked to meteorite impact craters in the field of astrophysics.

For the hypervelocity impact cratering experimental studies of projectiles penetrating semi-infinite concrete targets, $\mathrm{Wu}$ Kong et al. [1] performed steel projectile penetration tests on targets made from mortar with velocities ranging from 0.51 to $1.85 \mathrm{~km} / \mathrm{s}$, where projectiles with a diameter of $6 \mathrm{~mm}$ 
and length of $30 \mathrm{~mm}$ were used. Qian et al. [2] carried out impact experiments using tungsten alloy projectiles on concrete targets, with the impact velocity ranging from 1.97 to $3.66 \mathrm{~km} / \mathrm{s}$. The projectiles were $10.5 \mathrm{~mm}$ long by $3.45 \mathrm{~mm}$ in diameter. The experimental data of the impact craters were obtained and the cratering mechanism of the hypervelocity impact was analyzed by Qian et al. [2]. The dimension of the crater volume was found to be proportional to the kinetic energy of the projectile.

Holsapple [3,4] systematically introduced the "point source model" for calculating hypervelocity impact craters, which then became a classic model widely used in the field of celestial collisions. The point-source solution was obtained by making the approximation that the initial conditions could be described as a point source when dealing with nuclear explosions or impacts. Based on the point source solution, key dimensionless variables and function forms were proposed by means of dimensional analysis, and finally the crater model was determined by Holsapple [3,4]. Poelchau et al. [5-8] summarized the experimental results of the hypervelocity impact of spherical projectiles on geological material targets conducted by the Multidisciplinary Experimental and Modeling Impact Research Network (MEMIN) research unit and studied the effects of impact velocity, target density, target porosity, and other parameters on the impact craters. The major results comprised the projectile-target interaction, crater morphologies, cratering efficiencies in various nonporous and porous lithologies, in situ target damage, and the geophysical survey of experimental craters.

In the present paper, five shots of flat-nose long-rod steel projectiles impacting on semi-infinite concrete targets were conducted, with impact velocities ranging from 2117 to $3086 \mathrm{~m} / \mathrm{s}$. The crater diameter and depth as well as the crater volume were obtained. The scaling laws for crater volume impacted by a rod-shaped projectile were discussed and an empirical formula for crater volume was determined with the existing test data of Kong et al. [1] and Qian et al. [2]. The present experiment results were used to check the predictive ability for the crater volume, diameter, and depth of the empirical formula. Concrete fragments were collected from the target chamber after the impact experiments and the fragment mass was measured. The scaling laws for the size distribution of the concrete fragments were also discussed briefly.

\section{Experiment}

Five shots of long-rod projectiles were launched by a combustion two-stage light-gas gun and impacted the semi-infinite concrete targets with velocities ranging from 2117 to $3086 \mathrm{~m} / \mathrm{s}$. The experimental data included the crater dimensions and statistics of the concrete spalling fragments.

\subsection{Projectiles and Targets}

The flat-nose long-rod projectiles used were $40 \mathrm{CrNiMo}$ steel, $\sim 70 \mathrm{~mm}$ long by $7 \mathrm{~mm}$ diameter, and its density was $7.86 \mathrm{~g} / \mathrm{cm}^{3}$. The projectile material was heat-treated to a Rockwell " $\mathrm{C}$ " Hardness $\left(H R_{c}\right)$ of 29.8. The static yield strength and tensile strength of the projectile material were 920 and 1036 $\mathrm{MPa}$, respectively. The masses of the projectiles were close to $24 \mathrm{~g}$. The long-rod projectile was launched with the ring-type discarding sabot. The sabot was made from three segments of glass-reinforced polyetherimide that were serrated to encase the long-rod. Behind the sabot was a ring-like obturator to prevent gas leakage during launching. A picture of the long-rod projectile and the sabot is shown in Figure 1.

The maximum size of the concrete aggregate was less than $2 \mathrm{~mm}$ to eliminate the influence of aggregate size on the penetration performance of a relatively small-size long-rod. The concrete targets were wrapped by $3 \mathrm{~mm}$ thick steel tubes with a diameter of $600 \mathrm{~mm}$ and length of $400 \mathrm{~mm}$. The compressive strength of the concrete was $45 \mathrm{MPa}$, which was obtained from the compression test of $150 \mathrm{~mm}$-length cube specimens. The density of the concrete target was $2.18 \mathrm{~g} / \mathrm{cm}^{3}$. 


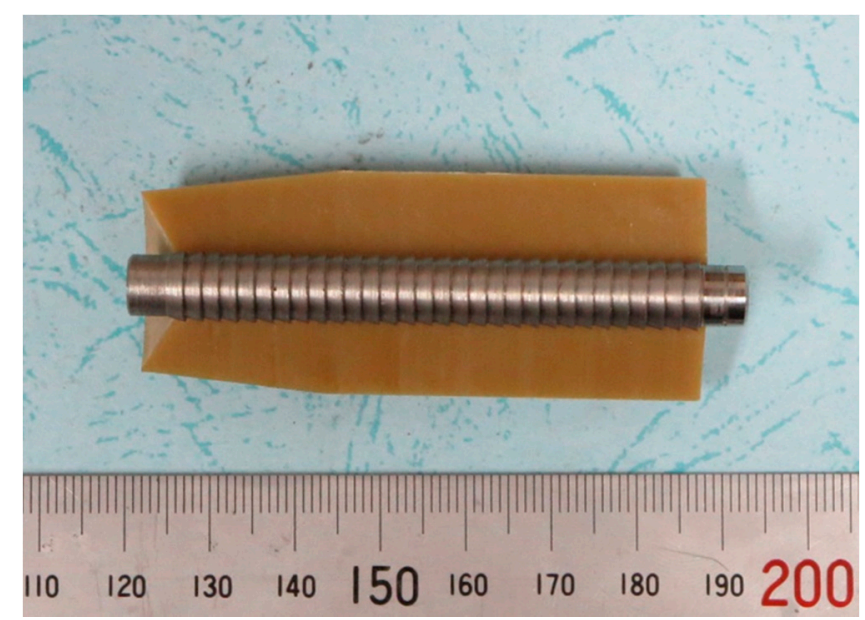

Figure 1. Long-rod projectile with sabot.

\subsection{Experimental Setup}

Tests were conducted at the Beijing Institute of Technology (BIT) using a two-stage light-gas gun of $30 \mathrm{~mm}$ caliber. In this gun, the driving force was provided by hydrogen combustion. A certain proportion of hydrogen, oxygen, and nitrogen was introduced into the combustion chamber under pressure, and the resultant mixture was electrically ignited to propel the piston in the pump tube. The experimental setup is shown in Figure 2. The velocity of the long-rod projectile was measured with a magnetic velocimeter. After the projectile flew out of the muzzle, the sabot was separated from the long-rod aerodynamically in the separation chamber filled with nitrogen gas. Then, the discarding sabot was intercepted by a central perforated steel plate fixed in front of the target (shown in Figure 2). The high-speed camera system was used to record the impact process. Typical photographs of the long-rod projectile during the flight before impacting the target are shown in Figure 3 and indicate that the projectile impacts the target almost perpendicularly.

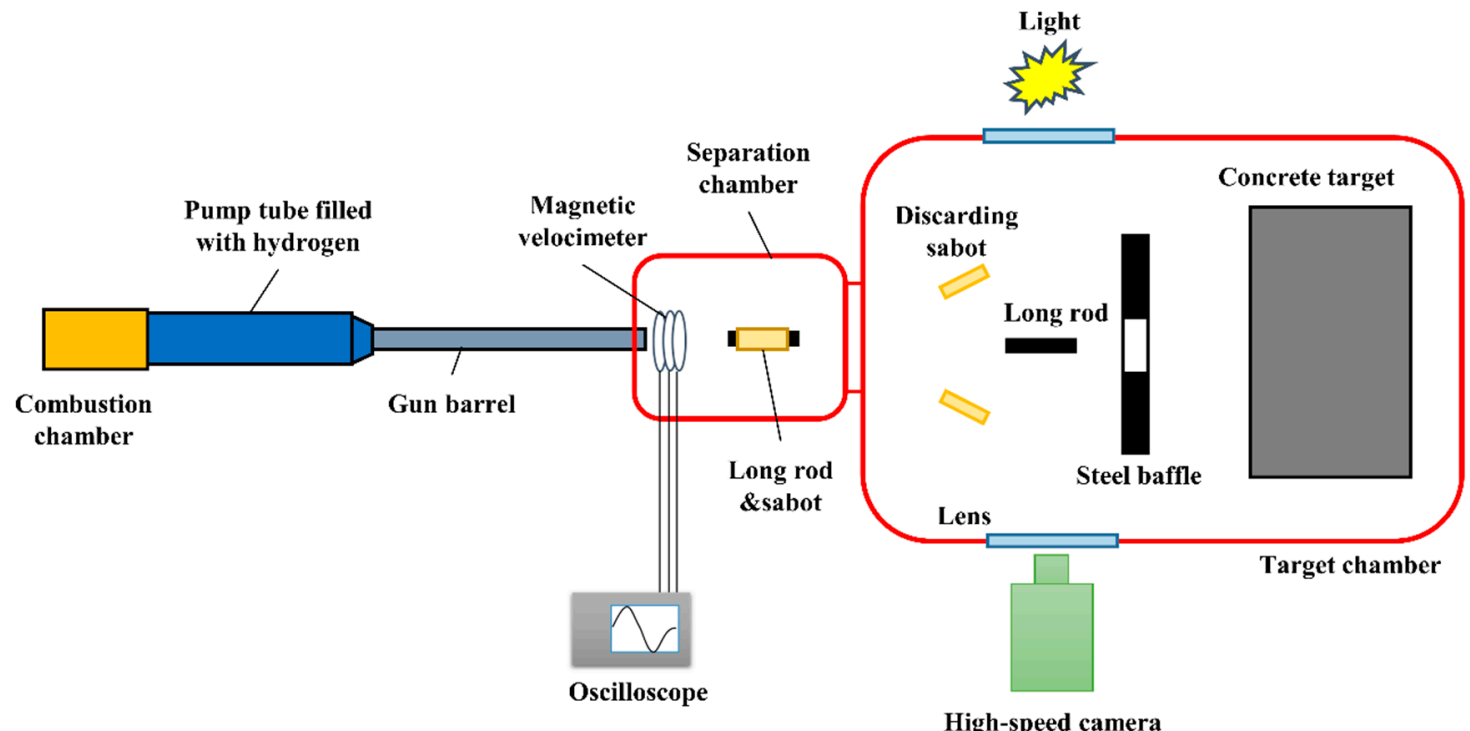

Figure 2. Schematic diagram of the testing system. 


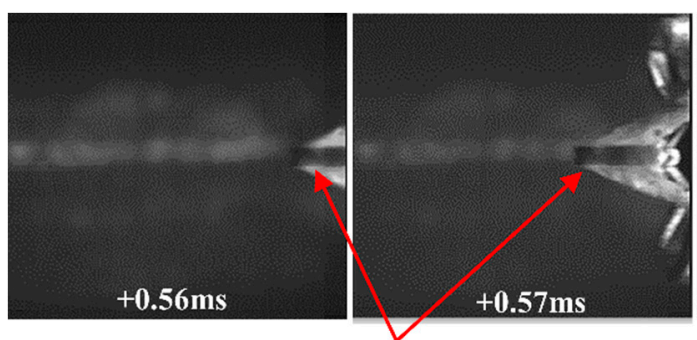

Long rod

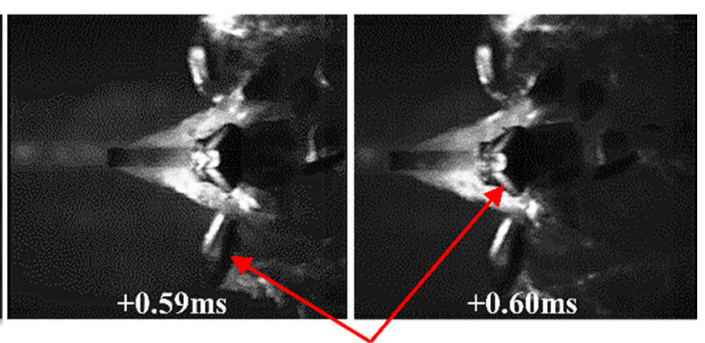

Sabot

Figure 3. Typical long-rod projectile photographs from the high-speed camera.

\subsection{Results}

The process of the long-rod penetrating the concrete target is shown in Figure 4 . Weak firelight was generated at the moment of the impact, then the long-rod projectile penetrated the target body. The concrete near the contact point shattered and splashed back. It is known that the tensile strength of concrete is much lower than its compressive strength. When the projectile impacted the concrete target, strong shock waves would be formed in the target, which can be several GPa or even several tens of GPa. The shock waves formed tensile waves after being reflected from the front of the concrete target, causing the concrete spallation.

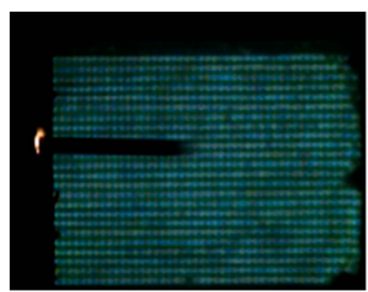

(a) $0 \mathrm{~ms}$

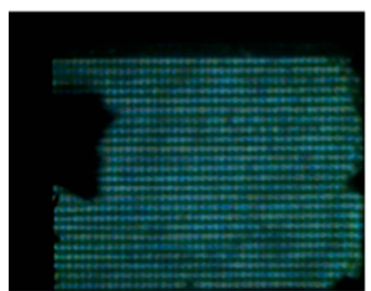

(e) $0.04 \mathrm{~ms}$

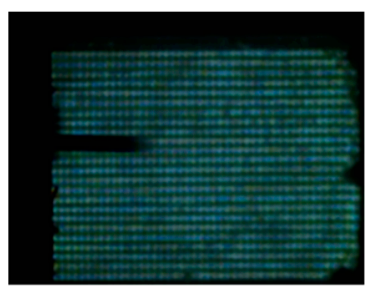

(b) $0.01 \mathrm{~ms}$

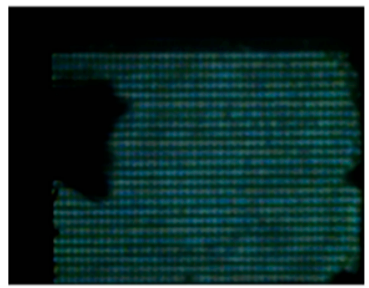

(f) $0.05 \mathrm{~ms}$

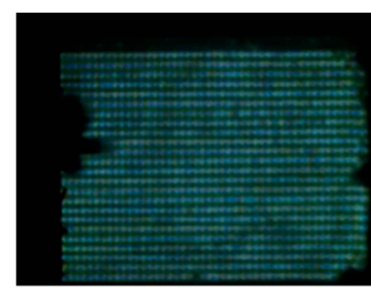

(c) $0.02 \mathrm{~ms}$

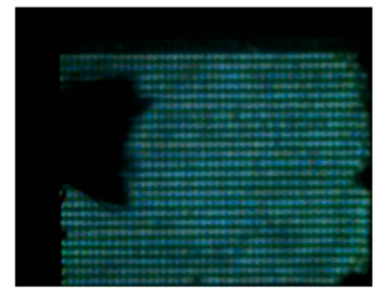

(g) $0.06 \mathrm{~ms}$

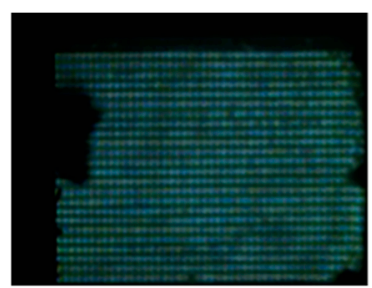

(d) $0.03 \mathrm{~ms}$

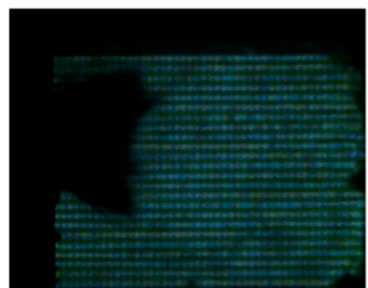

(h) $0.07 \mathrm{~ms}$

Figure 4. Typical photographs of the long-rod projectile penetrating a concrete target at $2117 \mathrm{~m} / \mathrm{s}$.

The damage of the concrete targets is shown in Figure 5 and the corresponding crater parameters are listed in Table 1 . The data listed in Table 1 includes the length $\left(L_{p}\right)$ and mass $\left(m_{p}\right)$ of the long-rod projectile; impact velocities; yaw angles; DOPs (depth of penetrations); and crater dimensions, where $D_{c}$ and $H_{c}$ are the equivalent diameter and depth of the crater and $V_{c}$ is the crater volume. The equivalent $D_{c}$ was obtained by measuring the crater area with the help of image recognition and calculating the diameter of the circle with the same area. According to the contour of the impact crater, the shape of the crater can be approximated as a spherical cap shape, as shown in Figure 6. 

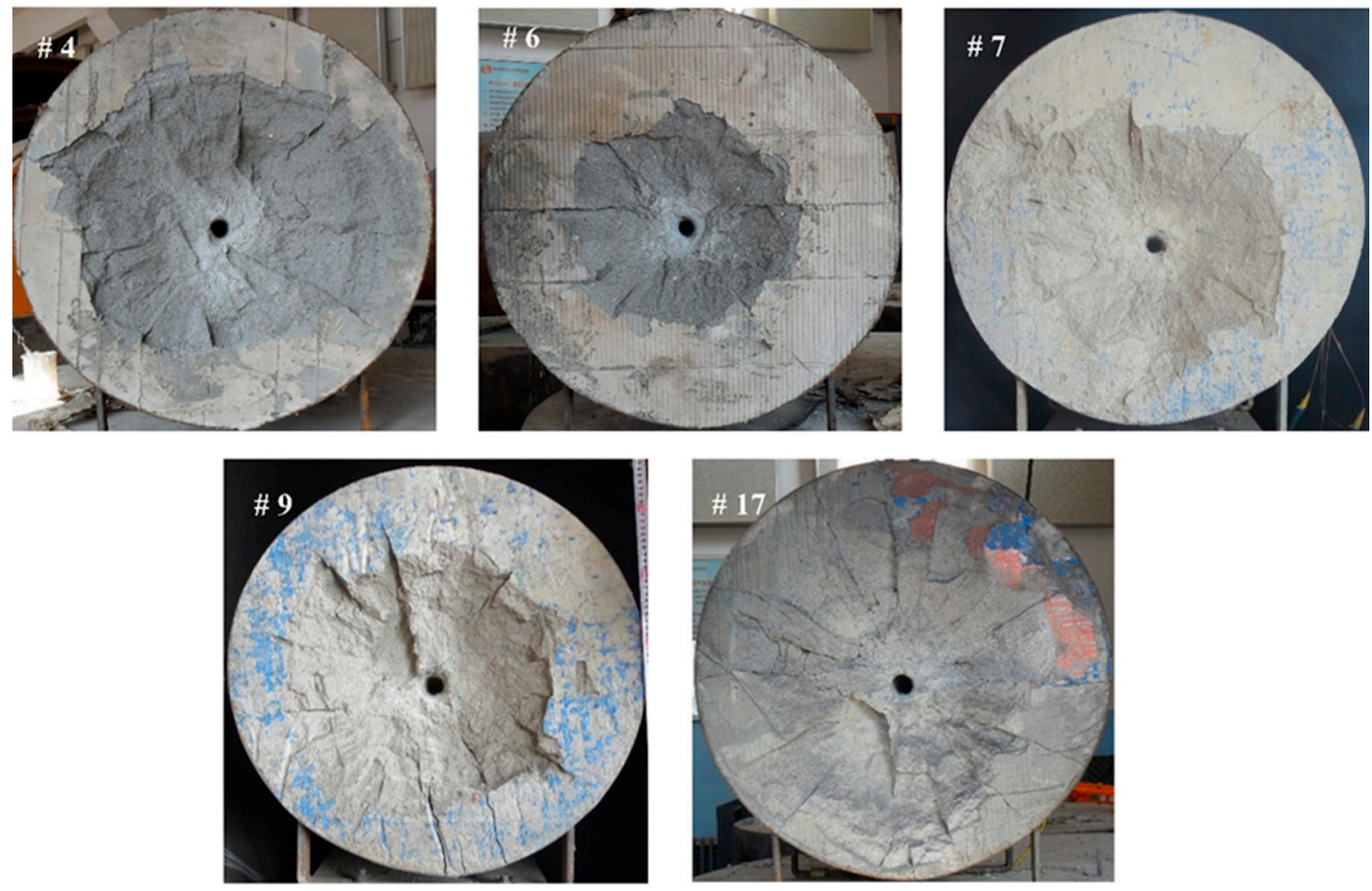

Figure 5. Frontal damage of concrete targets.

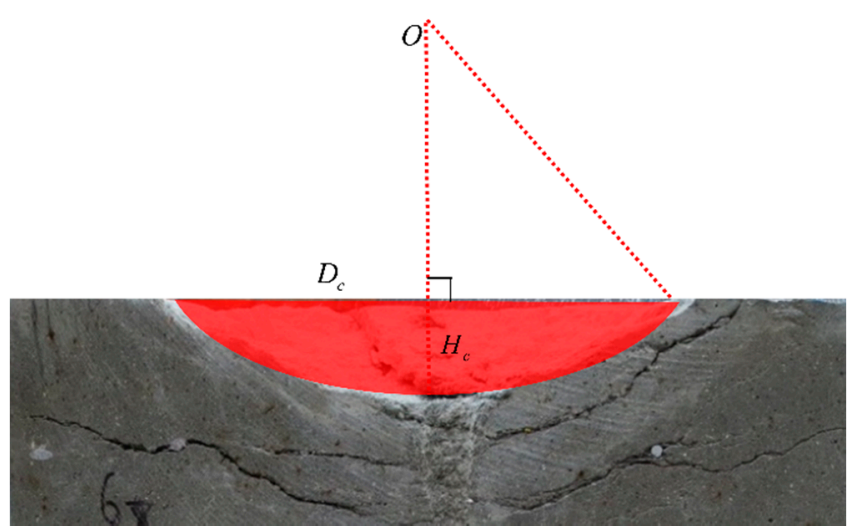

Figure 6. Sectional view of the typical crater for target \#9 with a $V_{0}=3083 \mathrm{~m} / \mathrm{s}$.

Table 1. Test results.

\begin{tabular}{|c|c|c|c|c|c|c|c|c|}
\hline \multirow{2}{*}{ Target No. } & \multicolumn{3}{|c|}{ Long-Rod Dimensions } & \multirow{2}{*}{$V_{0}(\mathrm{~m} / \mathrm{s})$} & \multirow{2}{*}{$\begin{array}{c}\text { Yaw } \\
\text { Angle }\left({ }^{\circ}\right)\end{array}$} & \multicolumn{3}{|c|}{ Crater Dimensions } \\
\hline & $m_{p}(\mathrm{~g})$ & $D_{p}$ & $L_{p}(\mathrm{~mm})$ & & & $D_{c}(\mathrm{~mm})$ & $H_{c}(\mathrm{~mm})$ & $V_{c}\left(\mathrm{~cm}^{3}\right)$ \\
\hline$\# 4$ & 24.26 & 6.98 & 69.83 & 2688 & 0.8 & 442.2 & 61 & 3959 \\
\hline$\# 6$ & 24.13 & 6.98 & 70.02 & 2117 & 1.2 & 321.1 & 49 & 1561 \\
\hline \#7 & 23.79 & 7.00 & 70.46 & 2220 & 0.5 & 357.2 & 59 & 2316 \\
\hline$\# 9$ & 23.99 & 7.02 & 70.32 & 3086 & 0 & 395.4 & 80 & 4388 \\
\hline$\# 17$ & 24.26 & 6.99 & 70.00 & 2494 & 0 & 384.8 & 52 & 3611 \\
\hline
\end{tabular}

Figure 7 presents the influence of the impact velocity on the crater dimensions. It is observed from Figure $7 \mathrm{a}$ that the non-dimensional equivalent crater diameter $\left(D_{c} / D_{p}, D_{p}\right.$ is the original long-rod projectile diameter) increased with the increasing impact velocity within the parametric range covered by the present experiment. When the velocity of the long-rod projectile was $3086 \mathrm{~m} / \mathrm{s}$, the equivalent crater diameter was up to 56 times the diameter of the projectile. Figure $7 \mathrm{~b}$ indicates that the non-dimensional 
crater depth $\left(H_{c} / D_{p}\right)$ generally increased with the increasing impact velocity, which was found similarly in flat-nose projectile penetration tests into mortar targets by Kong et al., 1. Besides this, it is obtained from Figure $7 \mathrm{c}$ that the non-dimensional crater volume $\left(V_{c} / V_{p}, V_{p}\right.$ is the original long-rod projectile volume) showed an increase with increasing impact velocity.
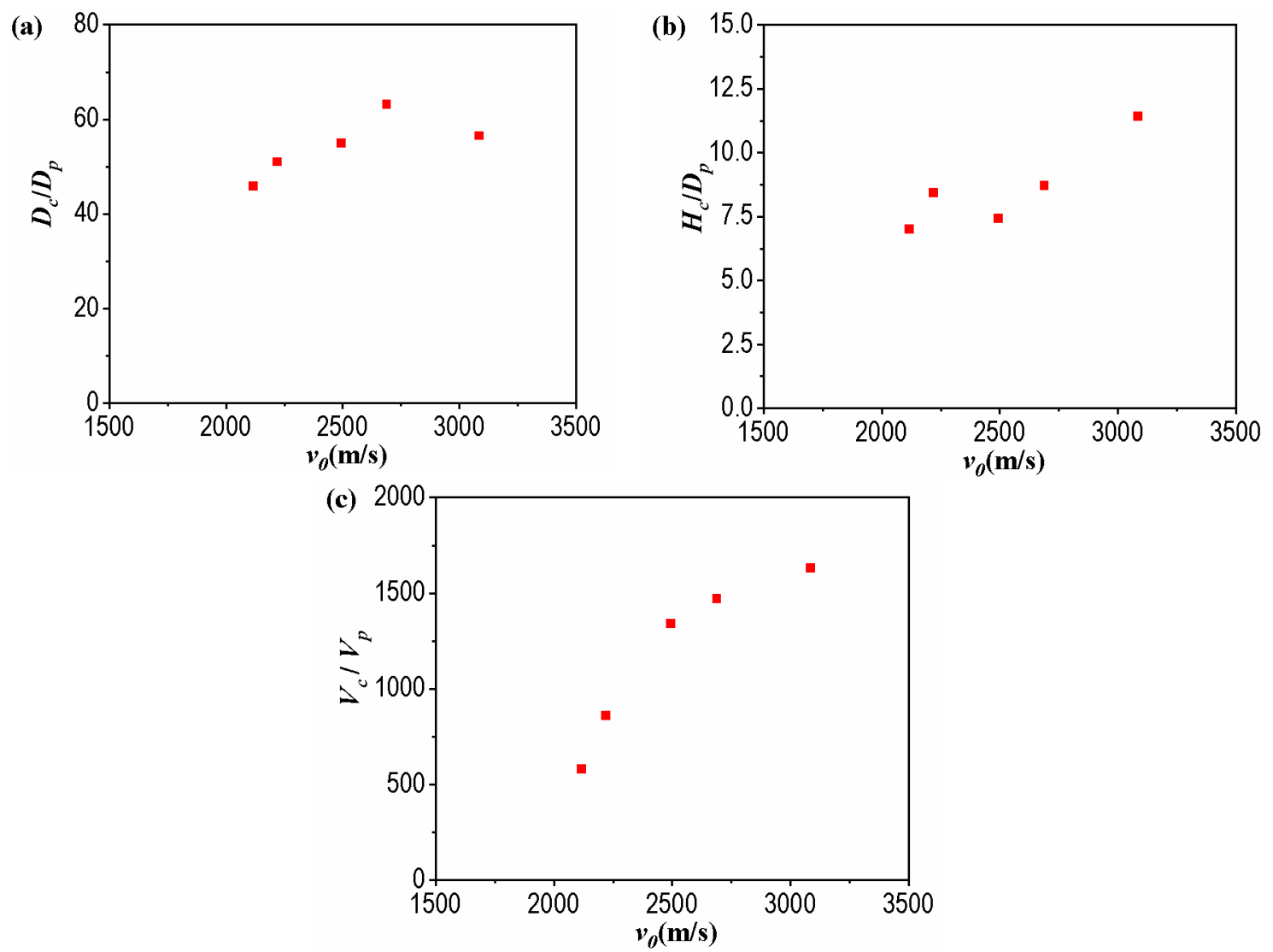

Figure 7. Influence of the impact velocity on (a) the non-dimensional equivalent crater diameter, (b) the non-dimensional crater depth, (c) the non-dimensional crater volume.

To analyze the effect of projectiles with different length to diameter ratios $\left(k_{p}\right)$ on impact craters, the test data of Kong et al. 1 and Qian et al. 2 are citied and compared with the present experimental results. The crater volume was related to the projectile volume $V_{p}$, and hence it is dimensionless. The relation between the dimensionless crater volume and the projectile kinetic energy for different length to diameter ratio projectiles is shown in Figure 8 in which the dotted lines represent the linear fit (the correlation coefficient $R^{2}$ from left to right are $0.98,0.97,0.98$ ) to the test data. The abbreviation "Exp." stands for the present experimental result. It can be obtained from Figure 8 that the dimensionless crater volume is greatly affected by the length to diameter ratio of the projectile. The volume of the crater increases almost linearly with the kinetic energy of the projectile.

The spalling concrete fragments were collected from the enclosed target chamber after impact experiments, as shown in Figure 9. Each piece of the concrete fragment more than $10 \mathrm{~g}$ was weighed and recorded. The fragments below $10 \mathrm{~g}$ were classified into two mass distribution intervals of $0.2 \sim 10 \mathrm{~g}$ and below $0.2 \mathrm{~g}$, and the total mass was counted separately. Figure 10 shows the mass distribution of the concrete fragments of different impact velocities. The total mass of the concrete fragments as well as the fragment mass of each interval increased with increasing impact velocity. Figure 11 presents the proportion of the fragment mass of each interval, which indicates that the proportion of the fragment mass of each interval was approximately the same at different impact velocities. 


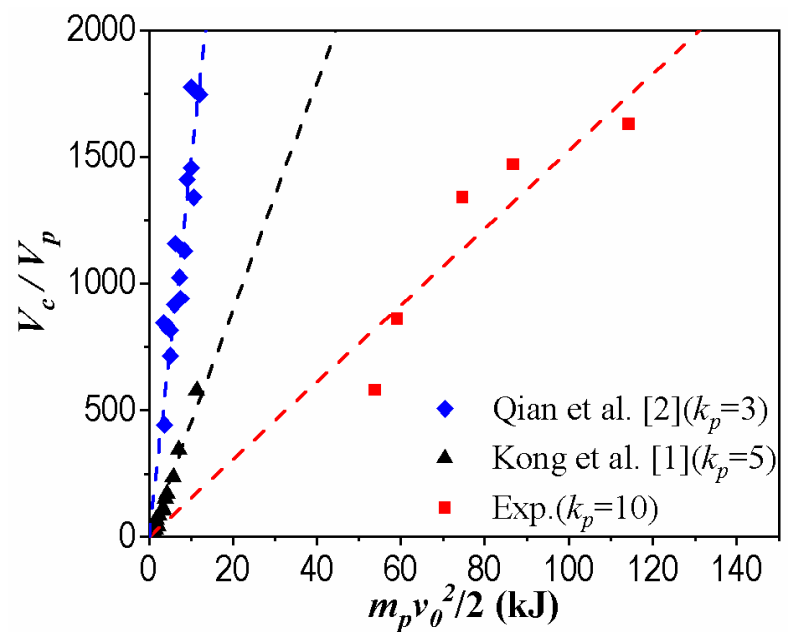

Figure 8. Non-dimensional crater volume vs. the projectile kinetic energy.

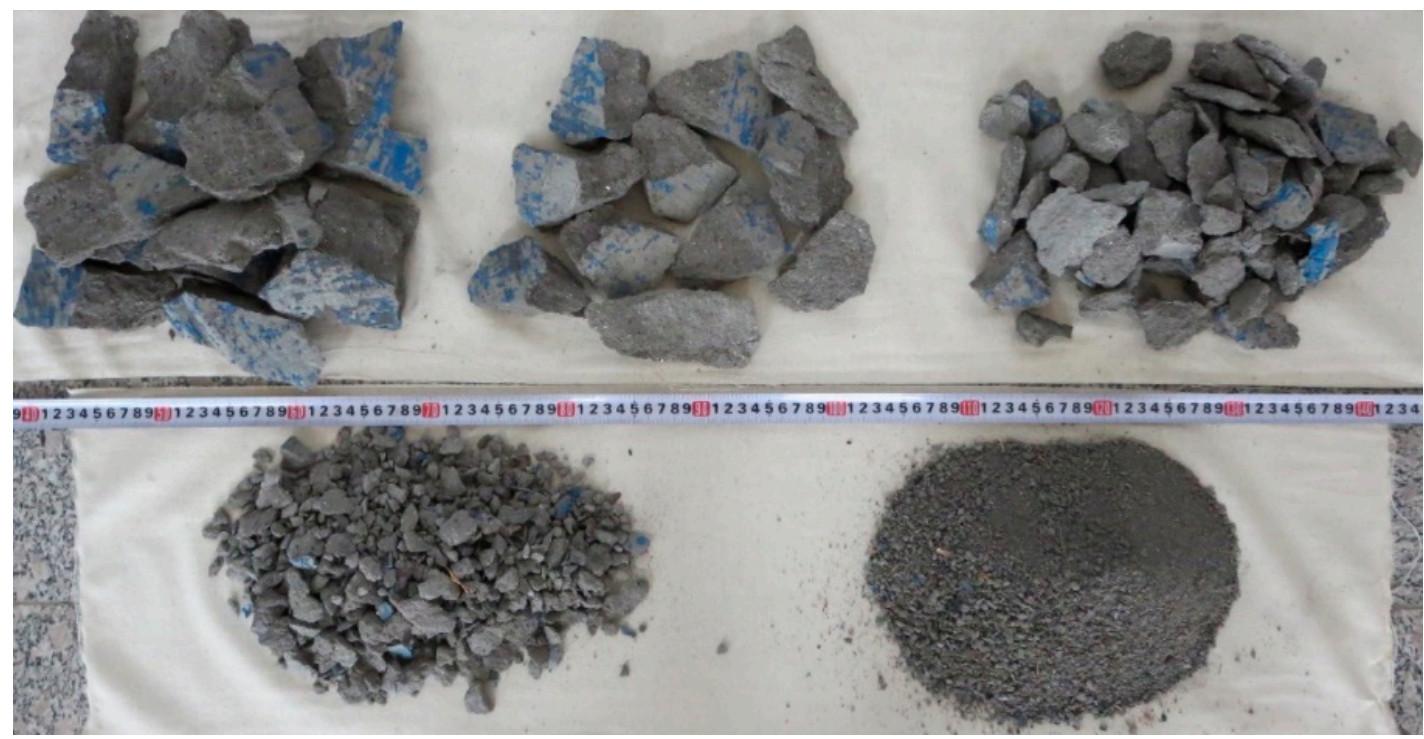

Figure 9. Collected concrete fragments after test \#9 (piled by more than $100 \mathrm{~g}, 50 \sim 100 \mathrm{~g}, 10 \sim 50 \mathrm{~g}$, $0.2 \sim 10 \mathrm{~g}$, less than $0.2 \mathrm{~g}$ ).

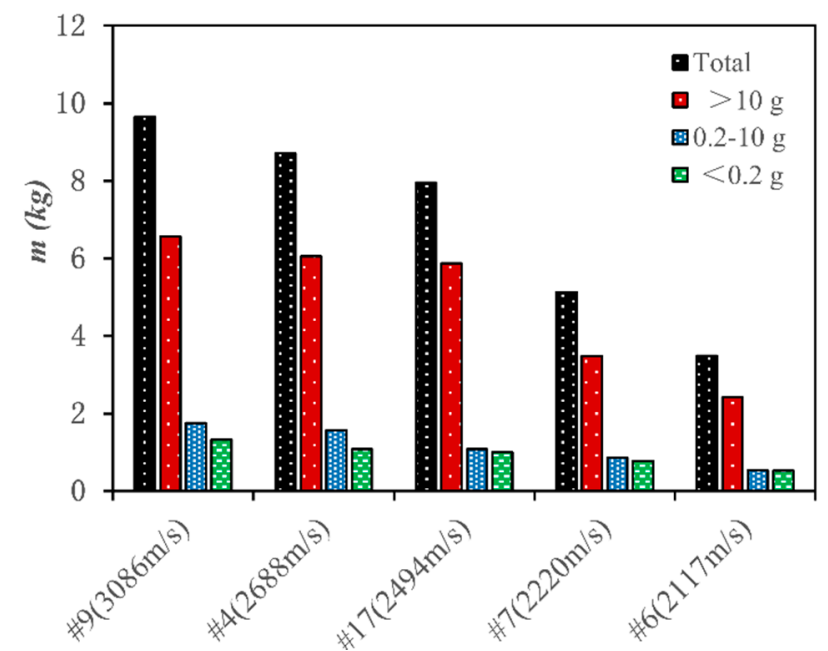

Figure 10. Mass distribution of the concrete fragments. 


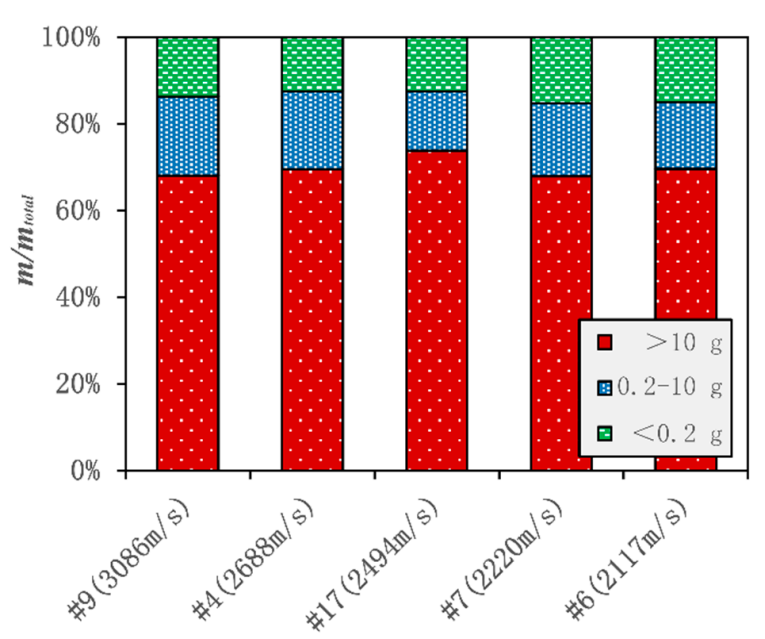

Figure 11. The proportion of fragment mass of each interval.

Figure 12 shows the cumulative distribution of fragments depending on the fragment's mass, $\mathrm{m}$. Figure 13 presents the normalization of the vertical axis of Figure 12. According to the processing method of Nishida et al. [9], when the vertical axis was divided by the impact velocity $(\mathrm{km} / \mathrm{s})$ raised to the power 1.5, all the results at five impact velocities lay almost on the following curve.

$$
N(m) / v_{0}^{1.5}=7.2 \exp (-0.0085 \mathrm{~m})+24 \exp (-0.06 \mathrm{~m}) .
$$

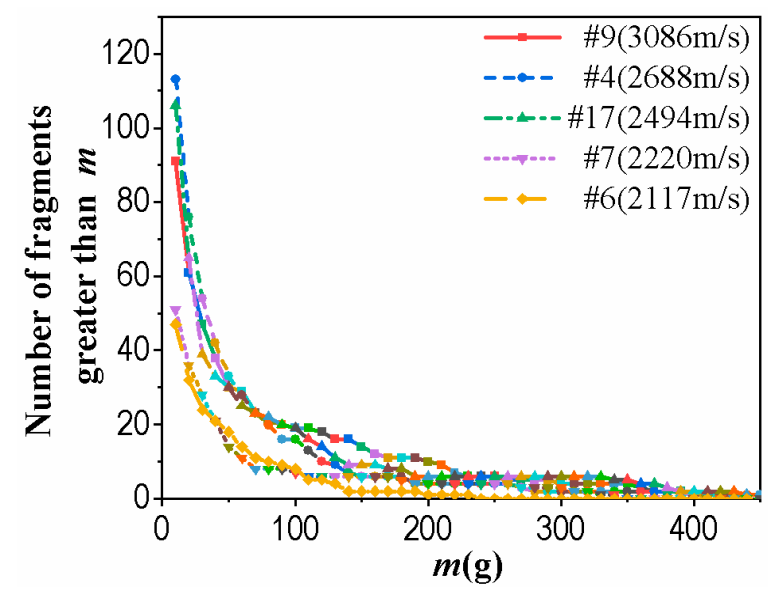

Figure 12. Concrete fragment mass distribution.

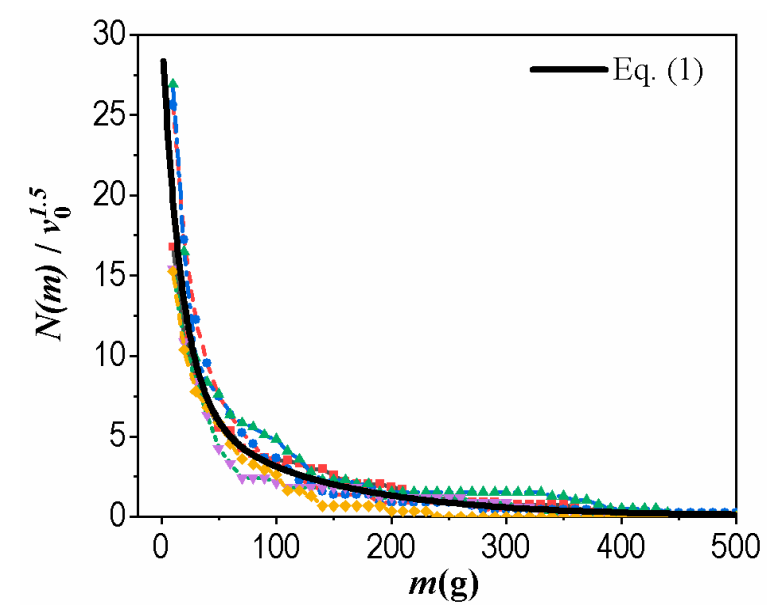

Figure 13. Results of the normalization of the mass distribution on the vertical axis. 
The form of Equation (1) is usually used in the statistics of impact-forming debris to characterize the distribution rules. It is important to note that this equation is simply a curve representing the trend within the measured range of fragment mass of $m \geq 10 \mathrm{~g}$. For the material and structure of the projectile and target in different situations, the parameters of Equation (1) will be different, and further experiments are required to determine the parameters.

\section{Analyses and Discussions}

\subsection{Scaling Theory for the Impact Crater}

$\pi$-group scaling is a useful tool for analyzing the factors affecting crater size. Holsapple 3 provided a generalized equation for the crater volume of spherical projectiles in strength-dominated impacts. Considering the effect of the length-to-diameter ratio $\left(k_{p}\right)$ of the long-rod projectile, the crater volume $V_{c}$ is determined by the listed variables:

$$
V_{c}=f\left(D_{p}, k_{p}, m_{p}, \rho_{p}, \rho_{t}, \sigma_{t}, v_{0}\right),
$$

where $D_{p}, m_{p}, \rho_{p}$, and $v_{0}$ are the long-rod projectile diameter, mass, density, and velocity. $\rho_{t}$ is the target density and $\sigma_{t}$ is a measure of target strength. In the case of Equation (2), there are seven parameters, with the three independent dimensions of mass, length, and time. Therefore, the crater volume can be expressed non-dimensionally and Equation (2) can be written as:

$$
\frac{V_{c}}{D_{p}^{3}}=f\left[k_{p}, \frac{m_{p}}{D_{p}^{3} \rho_{t}}, \frac{\rho_{t}}{\rho_{p}}, \frac{\rho_{t} v_{0}^{2}}{\sigma_{t}}\right]
$$

as

$$
\frac{\rho_{t} V_{c}}{m_{p}} \propto k_{p}^{u_{1}} \cdot\left(\frac{m_{p}}{D_{p}^{3} \rho_{t}}\right)^{u_{2}} \cdot\left(\frac{\rho_{t}}{\rho_{p}}\right)^{u_{3}} \cdot\left(\frac{\rho_{t} v_{0}^{2}}{\sigma_{t}}\right)^{u_{4}},
$$

or as

$$
\frac{V_{\mathrm{c}}}{V_{p}} \propto k_{p}^{v_{1}} \cdot\left(\frac{\rho_{t}}{\rho_{p}}\right)^{v_{2}} \cdot\left(\frac{\rho_{t} v_{0}^{2}}{\sigma_{t}}\right)^{v_{3}},
$$

where $V_{p}$ is the projectile volume. Here, $v_{3}$ is defined as $v_{3}=1$, which means that $V_{c}$ increases at the rate of energy scaling. The scaling exponents $v_{1}$ and $v_{2}$ should be determined for certain types of projectiles and target materials.

Kong et al., 1 conducted steel projectile penetration tests on mortar targets with the compressive stress of $50 \mathrm{MPa}$. The flat-nose cylindrical projectiles with a length-to-diameter ratio of 5 and a mass of $6.58 \mathrm{~g}$ were used in the test. The impact velocity ranged from 510 to $1850 \mathrm{~m} / \mathrm{s}$. Qian et al., 2 conducted tungsten alloy projectile penetration tests on concrete targets with a compressive stress of $42.7 \mathrm{MPa}$. Flat-nose cylindrical projectiles with a length-to-diameter ratio of 3 and a mass of $1.72 \mathrm{~g}$ were used in the test. The impact velocity ranged from 1970 to 3660 m/s. As shown in Figure 14, the experiment results of Kong et al., 1 and Qian et al., 2 were used to fit Equation (5), and the fitted function shown is:

$$
\frac{V_{c}}{V_{p}}=9.6 k_{p}^{-0.2} \cdot\left(\frac{\rho_{t}}{\rho_{p}}\right)^{3 / 2} \cdot \frac{\rho_{p} v_{0}^{2}}{\sigma_{t}} .
$$

This can be used as an empirical formula for predicting the crater volume of a rod-shaped projectile impacting a concrete-like target. Figure 15 shows the present experimental crater volumes as well as the calculating result of Equation (6), from which good match can be observed. 

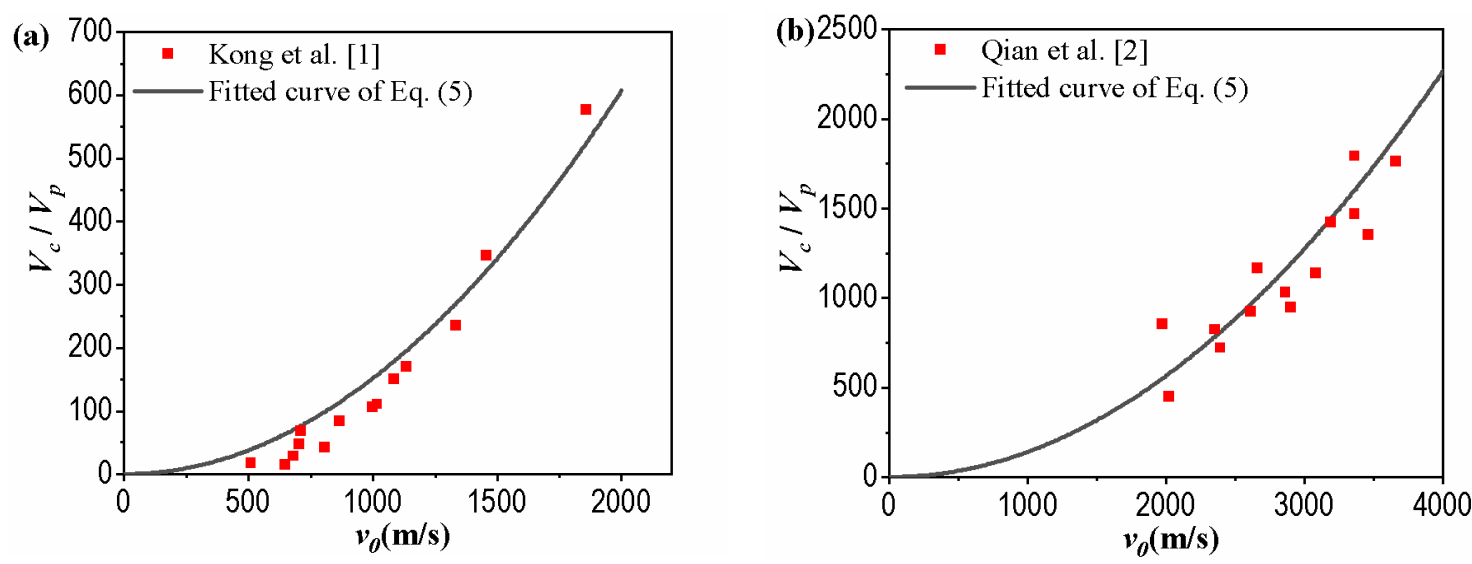

Figure 14. Experimental crater volumes and fitted curve of Equation (5) $\left(\mathbf{a} . R^{2}=0.986, \mathbf{b} . R^{2}=0.825\right)$.

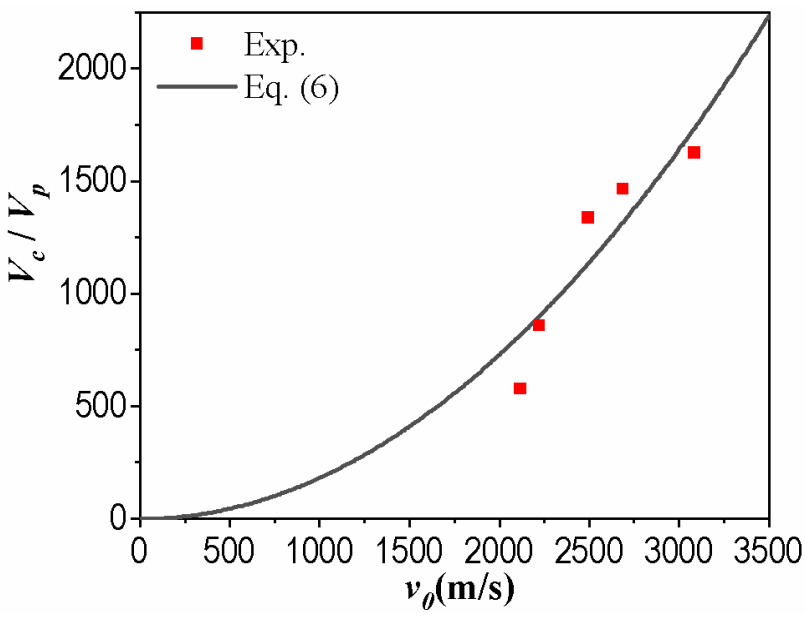

Figure 15. Experimental and predicted crater volumes.

From the present experimental result, the crater shape is similar to a spherical cap. The same phenomenon can be observed from the experimental results of Qian et al. 2. The ratio of crater depth to diameter $(\gamma)$ at different impact velocities of the present experiment as well as the test data of Kong et al. 1 is shown in Figure 16. The value of $\gamma$ is randomly distributed between 0.1 and 0.2 , which is not related to the impact velocity. Here, the empirical value of $\gamma$ is defined as 0.15 . Then, the empirical formulas for crater diameter $\left(D_{c}\right)$ and crater depth $\left(H_{c}\right)$ can be obtained as

$$
\begin{aligned}
& \frac{D_{c}}{D_{p}}=9.11 k_{p}^{0.267}\left(\frac{\rho_{t}}{\rho_{p}}\right)^{1 / 2}\left(\frac{\rho_{p} v_{0}^{2}}{\sigma_{t}}\right)^{1 / 3}, \\
& \frac{H_{c}}{D_{p}}=1.37 k_{p}^{0.267}\left(\frac{\rho_{t}}{\rho_{p}}\right)^{1 / 2}\left(\frac{\rho_{p} v_{0}^{2}}{\sigma_{t}}\right)^{1 / 3} .
\end{aligned}
$$

Figure 17 shows the crater diameters and the predicted result of the present experiment and Qian et al. [2]. It can be seen from Figure 17a that the present experimental results are all distributed near the predicted value of Equation. (7). The experimental crater diameter results in Figure $17 \mathrm{~b}$ are also distributed near the predicted value of Equation (7), except for few data points with small deviations. 


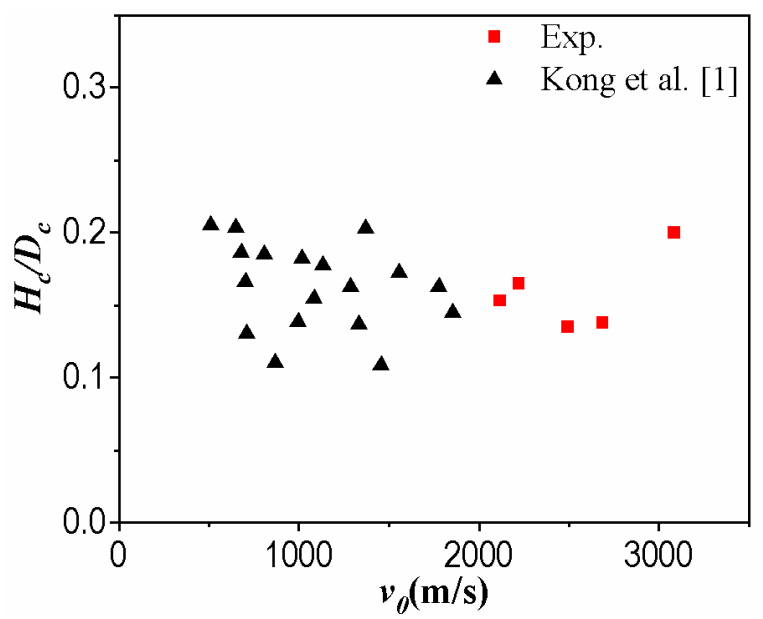

Figure 16. Influence of the impact velocity on the ratio of crater depth to diameter.
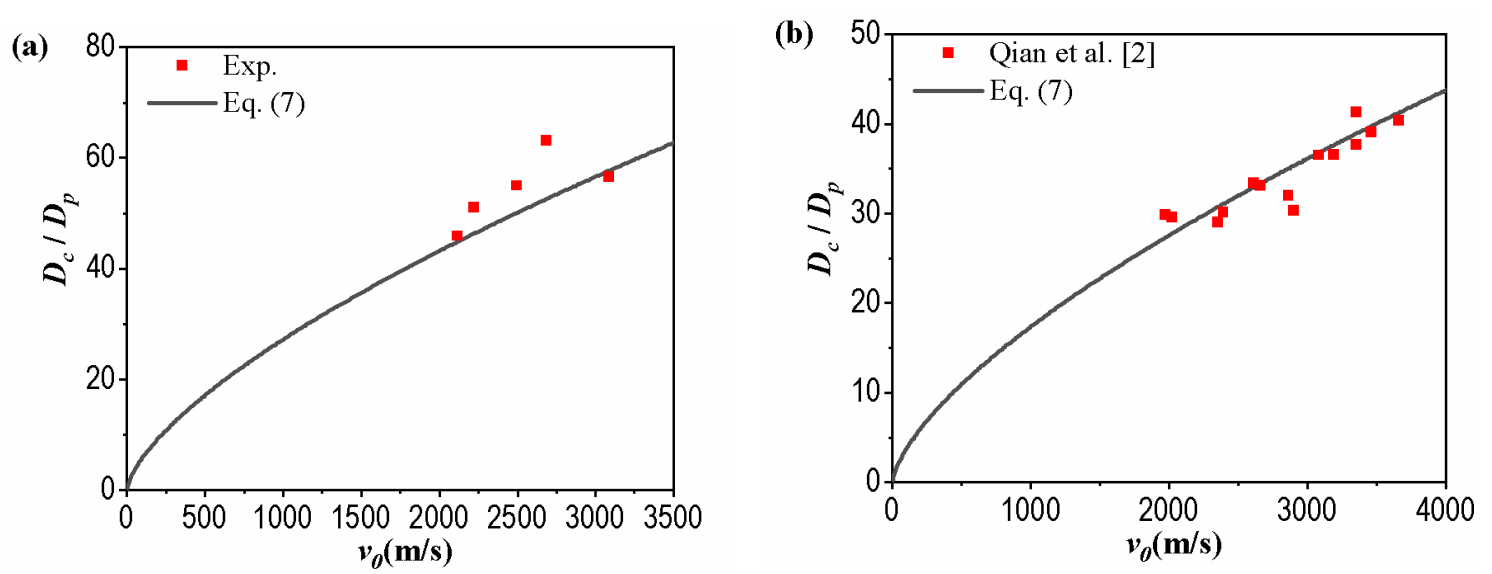

Figure 17. Experimental and predicted crater diameters: (a) present experiment, (b) Qian et al. 2.

\subsection{Further Discussions of $k_{p}$}

The empirical formula for the impact crater volume of the rod-shaped projectile has been obtained by Equation (6). The formula was improved by introducing the term $k_{p}$ based on the research work of Holsapple 4 to extend the crater volume calculation of spherical projectiles to rod-shaped projectiles. The influence of $k_{p}$ on the crater volume can be further discussed through the analysis of Equation (6). Figure 18 shows the crater volume results of different $k_{p}$ values when the projectile mass is constant. In this case, increasing the value of $k_{p}$ means increasing the projectile length while reducing the projectile diameter. It can be seen that the crater volume decreases with the increasing $k_{p}$ value under the same impact velocity and projectile mass. Figure 19 shows the crater volume results of different $k_{p}$ values when the projectile diameter is constant, which indicates that the crater volume increases with the increasing $k_{p}$ value under the same impact velocity and projectile diameter. Through the analysis of the above two cases, it can be seen that increasing the projectile diameter as well as increasing the projectile length can increase the size of the impact crater, and that the effect of projectile diameter on the crater size is greater than the effect of the projectile length. 


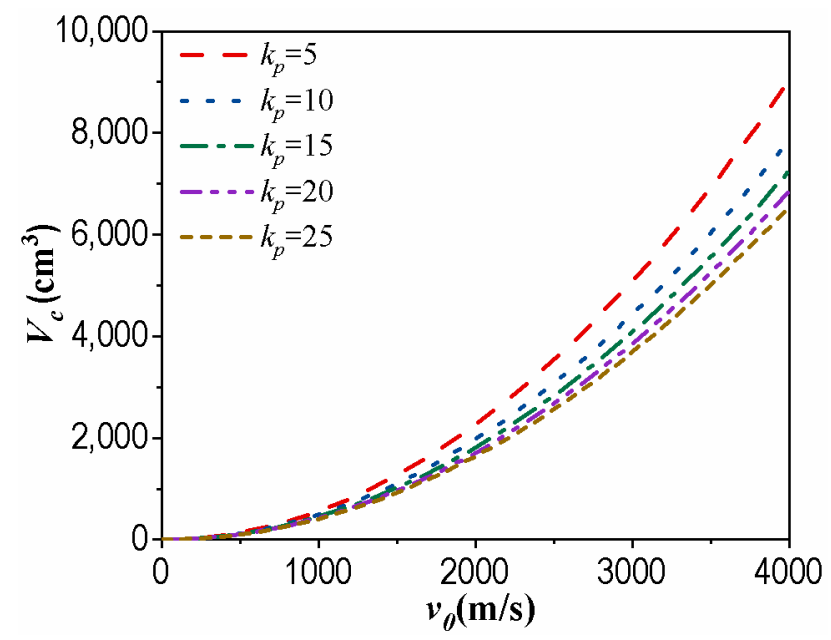

Figure 18. Crater volume of different length to diameter ratio $\left(k_{p}\right)$ values under the same projectile mass.

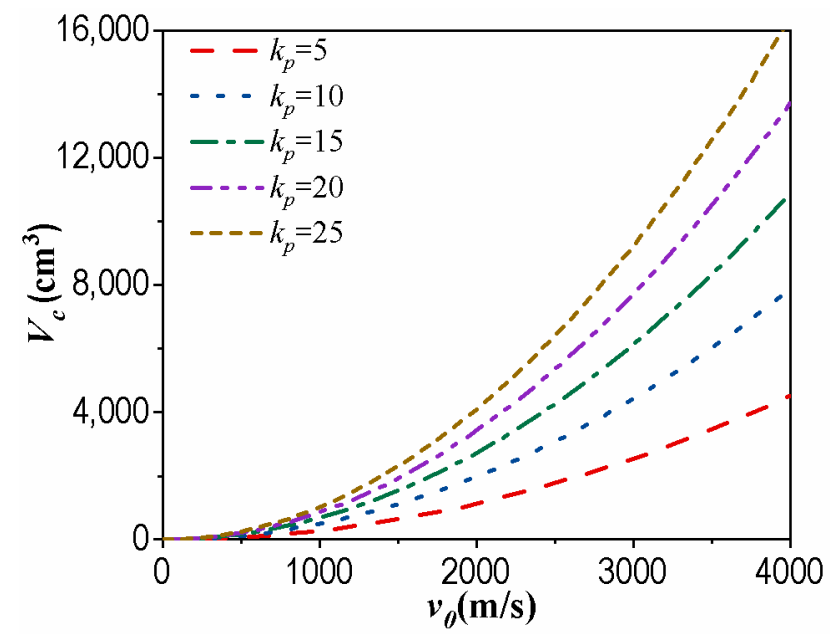

Figure 19. Crater volume of different $k_{p}$ values under the same projectile diameter.

\section{Conclusions}

Experiments to investigate the impact crater of hypervelocity long-rod projectiles in semi-infinite concrete targets have been conducted. The scaling laws for crater volume impacted by a rod-shaped projectile were discussed and the empirical formulas of crater volume, diameter, and depth were determined. It was found that the crater volume, crater diameter, and crater depth increased with the increasing impact velocity within the parametric range covered by the present experiment. The experimental results showed that the spalling concrete fragment mass increased with the increasing impact velocities, while the fragment distributions appeared to be independent of the impact velocity. The normalized fragment mass distribution was proportional to the impact velocity raised to the power 1.5. The predictive ability of the empirical formula for crater volume, diameter, and depth was proved to be reliable by comparison with the present experimental results. The analysis of the empirical formula shows the size of the impact crater varies greatly with the length-to-diameter ratio of the rod-shaped projectiles.

Author Contributions: Conceptualization, Q.Z.; Data curation, Y.L.; Formal analysis, Q.Z., Y.X. and C.S.; Funding acquisition, Q.Z.; Investigation, Y.L., Q.Z., Y.X., C.S., W.L., S.R. and R.L.; Methodology, Y.L. and Y.X.; Project administration, Q.Z.; Resources, Q.Z.; Supervision, Q.Z.; Validation, Y.L., Q.Z., Y.X., W.L. and R.L.; Writing—original draft, Y.L.; Writing—review and editing, Y.L. and Q.Z. All authors have read and agreed to the published version of the manuscript.

Funding: This work was supported by the National Key R\&D Plan of China (Grant no.2016YFC0801204).

Conflicts of Interest: The authors declare no conflict of interest. 


\section{References}

1. Kong, X.Z.; Wu, H.; Fang, Q.; Zhang, W.; Xiao, Y.K. Projectile penetration into mortar targets with a broad range of striking velocities: Test and analyses. Int. J. Impact Eng. 2017, 106, 18-29. [CrossRef]

2. Qian, B.W.; Zhou, G.; Li, J. Study of the Crater Produced by Hypervelocity Tungsten Alloy Projectile into Concrete Target. Trans. Beijing Inst. Technol. 2018, 38, 26-31.

3. Holsapple, K.A.; Schmidt, R.M. Point source solutions and coupling parameters in cratering mechanics. J. Geophys. Res. Solid Earth 1987, 92, 6350-6376. [CrossRef]

4. Holsapple, K.A. The Scaling of Impact Processes in Planetary Sciences. Annu. Rev. Earth Planet. Sci. 1993, 21, 333-373. [CrossRef]

5. Dufresne, A.; Poelchau, M.H.; Kenkmann, T.; Deutsch, A.; Hoerth, T.; Schaefer, F.; Thoma, K. Crater morphology in sandstone targets: The MEMIN impact parameter study. Meteorit. Planet. Sci. 2013, 48, 50-70. [CrossRef]

6. Poelchau, M.H.; Kenkmann, T.; Thoma, K.; Hoerth, T. The MEMIN research unit: Scaling impact cratering experiments in porous sandstones. Meteorit. Planet. Sci. 2013, 48, 8-22. [CrossRef]

7. Kenkmann, T.; Wünnemann, K.; Deutsch, A.; Poelchau, M.H.; Schäfer, F.; Thoma, K. Impact cratering in sandstone: The MEMIN pilot study on the effect of pore water. Meteorit. Planet. Sci. 2011, 46, 890-902. [CrossRef]

8. Poelchau, M.H.; Kenkmann, T.; Hoerth, T.; Schäfer, F.; Rudolf, M.; Thoma, K. Impact cratering experiments into quartzite, sandstone and tuff: The effects of projectile size and target properties on spallation. Icarus 2014, 242, 211-224. [CrossRef]

9. Nishida, M.; Hiraiwa, Y.; Hayashi, K.; Hasegawa, S. Scaling laws for size distribution of fragments resulting from hypervelocity impacts of aluminum alloy spherical projectiles on thick aluminum alloy targets: Effects of impact velocity and projectile diameter. Int. J. Impact Eng. 2017, 109, 400-407. [CrossRef]

(C) 2020 by the authors. Licensee MDPI, Basel, Switzerland. This article is an open access article distributed under the terms and conditions of the Creative Commons Attribution (CC BY) license (http://creativecommons.org/licenses/by/4.0/). 